\title{
DETECÇÃO DE PROBLEMAS VISUAIS E AUDITIVOS DE ESCOLARES EM RIBEIRÃO PRETO: ESTUDO COMPARATIVO POR NÍVEL SÓCIO-ECONÔMICO*
}

\author{
Maria Aparecida Tedeschi Cano** \\ Graciette Borges da Silva***
}

A avaliação das funções visuais e auditivas dos alunos ingressantes na $1^{a}$ série do $1^{0}$ grau é considerada uma ação básica de saúde do escolar.

A criança, ao ingressar na primeira série, inicia (ou continua) o processo de alfabetização, considerado um dos mais importantes da área educacional e necessita, portanto da visão e audição normais (ou com correção) para que esse processo seja facilitado.

Neste trabalho, procuramos estudar os distúrbios visuais e auditivos dos escolares de Ribeirão Preto, de diferentes estratos sociais, nos aspectos de detecção precoce, encaminhamento dos casos e solução ou não, pela família e escola, dos problemas encontrados.

UNITERMOS: Escolar, detecção precoce, visão, audição, estratificação social, família, professor

\footnotetext{
*Resumo de tese apresentada à Escola de Enfermagem de Ribeirão Preto - USP, para obtenção do grau de doutor

**Professor Doutor do Departamento de Enfermagem Materno-Infantil e Saúde Pública da Escola de Enfermagem de Ribeirão Preto da Universidade de São Paulo

***Professor Doutor do Departamento de Enfermagem Psiquiátrica e Ciências Humanas da Escola de Enfermagem de Ribeirão Preto da Universidade de São Paulo
} 


\section{Introdução}

A avaliação das acuidades visuais e auditivas dos alunos ingressantes na $1^{\mathrm{a}}$ série do $1^{\circ}$ grau é considerada uma ação básica de saúde do escolar.

A criança inicia, nessa fase, seu processo formal de ensino-aprendizagem, considerado um dos momentos mais importantes da socialização e necessita de visão e audição normais (ou com correção adequada) para que esse processo seja facilitado.

A literatura aponta as deficiências visuais e auditivas como um dos fatores responsáveis pelo baixo rendimento escolar. Segundo $Z^{2} N_{N}{ }^{11}$, muitos alunos são encaminhados para classes especiais destinadas a crianças com baixo rendimento quando, na realidade, têm uma visão precária, não sendo, portanto mentalmente deficientes. SELIGMAN ${ }^{6}$ relata um trabalho realizado em Porto Alegre (RS), onde $4 \%$ dos escolares (da rede pública) acometidos de problemas auditivos não tinham bom rendimento escolar.

Uma criança com visão e audição deficientes pode Ter seu desempenho escolar prejudicado; entretanto, os elevados índices de fracasso escolar, entre nós, não se explicam apenas por essas deficiências.

SPRENGER et al. ${ }^{8}$ referem-se a diversos obstáculos que interferem no processo ensino-aprendizagem e que têm raízes não só na diversidade de técnicas de alfabetização e na própria organização da escola mas nas precárias condições de vida dos alunos.

Nosso interesse pelos problemas visuais e auditivos dos escolares surgiu a partir de nossa vivência profissional quando desenvolvemos atividades como uma das coordenadoras de um Programa de Saúde Escolar junto às escolas da rede oficial de ensino de Ribeirão Preto.

Este Programa iniciou-se em 1980, objetivando atender as solicitações de uma escola carente da periferia da cidade para prestarmos assistência de saúde a seus alunos e contou com a participação de discentes de graduação de enfermagem. Em 1982, a convite do Secretário da Saúde do município, ampliamos o Programa para uma escola municipal de $1^{\circ}$ grau, também da periferia da cidade. Em 1985, a Escola de Enfermagem assinou um convênio com a Fundação de Assistência ao Estudante (FAE), órgão ligado ao MEC, e a Secretaria Municipal da Saúde. O Programa passou a ser denominado Programa de Assistência Primária à Saúde do Escolar (PROASE) tendo sido contratados, inicialmente, para a sua execução, alguns profissionais (enfermeiro, pediatra, pedagogo, otorrinolaringologista) e, ao expandir-se, outros profissionais foram contratados (psicólogos, fonoaudiólogos). Hoje, o PROASE envolve todas as escolas da rede oficial de ensino de Ribeirão Preto, estaduais e municipais, onde são desenvolvidas atividades educativas e de promoção de saúde.

As atividades de assistência à saúde individual - exame médico do escolar, urgências e problemas de saúde em geral - a nível de referência primária e secundária, são realizadas nas 
Unidades Básicas de Saúde (UBS) e o atendimento ao escolar com distúrbio de aprendizagem é realizado na Unidade Básica e Distrital de Saúde (UBDS).

Tem sido meta do PROASE o estabelecimento de um Programa de Saúde Coletiva, planejado e desenvolvido por uma equipe multiprofissional.

Pesamos que a solidificação do PROASE, em Ribeirão Preto, só foi possível graças ao envolvimento e interesse de alguns profissionais, dos órgãos oficiais de saúde e educação do município e do incentivo inicial da FAE, aliados a uma conjuntura política que, na década de oitenta, possibilitou espaço à saúde coletiva.

Durante esses anos de envolvimento com a saúde escolar, têm-se nos deparado, freqüentemente, inúmeras dificuldades tanto no que se refere à detecção de problemas visuais e auditivos, como a resolubilidade dos casos detectados.

Para o desenvolvimento da pesquisa empírica relativa a essa problemática, partimos de algumas hipóteses genéricas, abrangendo os aspectos acima citados:

01. Os pais com melhor nível sócio-econômico e maior grau de instrução conseguem perceber, mais precocemente, distúrbios de visão e audição de seus filhos;

02. O professor, pelo contato direto com os alunos durante o período de alfabetização, tem condições de detectar problemas de visão e audição que estes venham a apresentar;

03. Uma vez detectados, na escola, problemas visuais ou auditivos dos alunos, a sua resolução extrapola o âmbito escolar.

\section{Metodologia}

Neste trabalho, procuramos estudar os distúrbios visuais e auditivos dos escolares de Ribeirão Preto de diferentes estratos sociais, nos aspectos de detecção precoce, encaminhamento dos casos e solução do problema pela escola e família.

Todas as sociedades humanas estão estratificadas de alguma forma, o que quer dizer que indivíduos ou grupos estão hierarquicamente dispostos em uma escala social. Estrato social é um conceito que pode ser entendido como o conjunto de pessoas que têm em comum um número determinado de características mensuráveis, ou seja, status comum e que pode ser definido por distintos critérios (STAVENHAGEN ${ }^{9}$, SILVA $^{7}$ ). Na perspectiva que nos orienta e tendo em vista $p$ desenvolvimento da pesquisa, selecionamos alguns critérios de estratificação social para estudar os fatores que interferem na detecção precoce dos distúrbios visuais e auditivos entre os escolares.

Iniciamos a investigação a partir da Escola, uma vez que ela espelha, em certos aspectos, a sociedade na qual se insere, reproduzindo, em parte, sua estrutura. 
Fizemos um levantamento das escolas da cidade (nomes e endereços) constatando que Ribeirão Preto possuía, 1990, 71 escolas de $1^{\circ}$ grau, que estratificamos segundo o tipo de clientela que as freqüentava em: carentes, mistas, de nível médio e particulares. As escolas carentes, em número de 19, localizadas em bairros periféricos, atendem crianças provindas de famílias de baixa renda. As escolas mistas, que são 34, estão localizadas no centro da cidade, nos conjuntos habitacionais ou bairros próximos ao centro. Seu alunado compõe-se tanto de crianças provindas de famílias com melhores condições econômicas como de crianças carentes. As seis escolas de nível médio existentes foram assim classificadas por serem freqüentadas por crianças de melhores condições econômicas e sociais. Localizam-se em bairros que possuem infra-estrutura sanitária, servidos por várias linhas de ônibus, possuindo moradias com aluguéis (em 1990) entre 2 e 5 salários mínimos. As 12 escolas particulares foram agrupadas, segundo a mensalidade escolar, em escolas com mensalidades de até $1 / 2$ salário mínimo (num total de 7 ) e com mensalidades de 1 salário mínimo e mais (num total de 5).

Tabela I - Estratificação das escolas em mistas, carentes e de nível médio, segundo a clientela. Ribeirão Preto, 1990.

\begin{tabular}{|c|c|c|c|c|}
\hline $\begin{array}{c}\text { ESTRATIFICAÇÃO } \\
\text { ESCOLAS }\end{array}$ & CARENTE & MISTA & NÍVEL MÉDIO & TOTAL \\
\hline Estaduais & 18 & 29 & 06 & 53 \\
\hline Municipais & 01 & 05 & - & 06 \\
\hline Particulares & - & - & - & 12 \\
\hline TOTAL & 19 & 34 & 06 & 71 \\
\hline
\end{tabular}

Esta estratificação foi realizada com base nas informações dos técnicos da Secretaria Municipal da Educação e da Delegacia de Ensino e em nossa vivência pessoal.

Terminado esse trabalho de construção dessa tipologia para as escolas, optamos, em princípio pelo sorteio de uma de cada grupo, conscientes de que a escola sorteada representaria o estrato no qual estava listada. Assim, nossa amostra inicial seria de 4 escolas; entretanto, decidimos ampliá-la, incluindo, intencionalmente, outras escolas, pelas razões explicitadas a seguir. 
No que se refere à escola carente, sorteamos uma estadual e incluímos a única considerada carente dentre as municipais. Dentre as escolas particulares, resolvemos considerar somente as que apresentam mensalidade de 1 ou mais salários mínimos, onde supúnhamos encontrar clientela mais diferenciada economicamente. Sorteamos uma escola e decidimos incluir a que apresenta a maior mensalidade.

Por sua vez, ao manusearmos as listas de triagem visual realizada nas escolas da rede oficial de ensino de Ribeirão Preto para serem encaminhadas à "campanha dos óculos escolar", promovida pelo governo do Estado de São Paulo, chamou-nos a atenção o fato de 2 escolas estaduais (uma mista e uma de nível médio, segundo nossa estratificação) não apresentarem nenhum aluno com distúrbio de visão, após os testes realizados pelos professores, o que nos levou, a incluí-las nas amostras (dados o caráter inusitado desse fato).

Resolvemos, também, incluir uma escola carente (estadual) onde o médico otorrinolaringologista do PROASE, já havia realizado a triagem audiométrica dos alunos, utilizando a mesma técnica e o mesmo audiômetro portátil que adotaríamos em nossa pesquisa (técnica esta para a qual ele já nos havia instruído e treinado), sendo que os pais das crianças com problemas auditivos não haviam ainda sido entrevistados.

Com o sorteio e as inclusões que consideramos oportunas, a amostra da pesquisa abrangeu 9 escolas (12,6\% do total).

Nossa população alvo foram crianças de $1^{\mathrm{a}}$ série de 6 a 7 anos, iniciando, portanto, o processo de alfabetização.

Como não nos era possível investigar todas as crianças de $1^{\text {a }}$ série de cada escola, resolvemos sortear uma classe de cada duas das escolas da amostra, para a realização dos testes para medir a acuidade visual e auditiva.

Os testes realizados não tinham o objetivo de diagnóstico, mas apenas o de triagem e seleção das crianças que apresentam alguma dificuldade de visão ou audição.

Antes dessa etapa elaboramos um plano piloto, visando a padronizar os métodos de triagem, contando para essa atividade com a colaboração de 4 alunas de graduação em enfermagem, que receberam treinamento.

Para a avaliação da acuidade visual, foi utilizada a tabela de Snellen, segundo a orientação da Secretaria de Estado da Saúde. As avaliações audiométricas foram realizadas com audiômetro portátil simplificado, adotado pelo PROASE em 1985 e que foi montado pelo Departamento de Fisiologia da Faculdade de Medicina de Ribeirão Preto.

Os testes, na medida do possível, foram realizados nas salas menos ruidosas da escola, como bibliotecas, dispensas e sala dos diretores.

Todas as crianças que apresentaram dificuldade no teste foram visitadas em sua casa, onde entrevistávamos os pais e fazíamos o encaminhamento para o Ambulatório de Referência de Especialidades (ARE) ou Ambulatório do Hospital das Clínicas da Faculdade de Medicina de 
Ribeirão Preto, caso a família não tivesse recursos.

Durante o plano piloto, testamos, pessoalmente, os formulários elaborados para as entrevistas com os pais, professores e diretores, nos quais buscamos levar em conta as críticas de THIOLLENT ${ }^{10}$ a esse instrumento de coleta de dados. Ele nos chama a atenção para alguns aspectos importantes desconsiderados na pesquisa convencional na área das ciências sociais: a pseudo neutralidade dos instrumentos de coleta de dados, a imposição da problemática de interesse do pesquisador e a distância cultural freqüentemente observável entre pesquisador e pesquisados.

Foram testadas as acuidades visual e auditiva de 528 alunos, no período de março a setembro de 1990, dos quais 140 freqüentavam escolas carentes; 146 escolas mistas; 180 escolas particulares e 62 escolas de nível médio. Essa diferença do número de crianças por escola explica-se pelo número diferente de classes de $1^{\mathrm{a}}$ série existentes em cada estabelecimento e pelo tamanho das classes.

Dos 528 alunos testados, 38, ou seja, 7,2\% da amostra, apresentaram algum distúrbio visual ou auditivo. Considerando-se que um mesmo aluno passou pelos dois testes, mas, em algumas situações, compareceu para apenas um, foram realizados 445 testes de acuidade visual e 499 auditivos.

\section{Resultados e discussão}

\section{Do teste de visão}

Dos 445 alunos avaliados, 28 (6,3\%) apresentaram um distúrbio de visão e 12 (2,7\%) já usavam óculos.

A porcentagem encontrada é pouco inferior aos dados da literatura, que apontam índices de distúrbio visual em torno de 10\%.

Classificando-se esses 28 alunos segundo a escola que freqüentavam, verificamos que 9 (32\%) pertenciam a escola mista; 12 (42,8\%) à escola carente; 5 (17,8\%) pertenciam à escola particular e 2 (7,14\%) à escola de nível médio.

Se somarmos o número de alunos de escolas carentes e mistas, observamos que este é maior que a soma dos alunos das escolas particulares e de nível médio. Entretanto, apesar dessa constatação, não podemos afirmar que a incidência de problemas visuais tenha raízes sócio-econômicas. Na literatura especializada, as ametropias ou vícios de refração (miopia, hipermetropia e astigmatismo) patologias oculares mais incidentes entre escolares - são causadas pelo crescimento anormal do olho no que se refere à distância entre a córnea e a retina, anormalidades estas, determinadas por problemas genéticos. 


\section{Do teste de audição}

Dos 449 alunos testados, 10 (2\%) apresentaram distúrbio auditivo e 7 (1,4\%) problemas de fala, sem comprometimento auditivo.

Duas pesquisas, a de SELIGMAN ${ }^{6}$, realizada no Rio Grande do Sul e a de BEVILACQUA $^{2}$, na cidade de São Paulo, apresentam índices de distúrbios auditivos em torno de $10 \%$. Os dados que encontramos estão bem aquém dessa percentagem, mas bem próximos dos de ANDRADE ${ }^{1}$, em investigação realizadas em Pradópolis e dos de HESIKI ${ }^{4}$, em Botucatu, com índices em trono de 2,3\%.

Os baixos índices por nós encontrados $(2,1 \%)$ talvez possam ser explicados pelo fato de termos trabalhado com crianças de diversos estratos sociais enquanto que, na literatura voltada para esse tipo de problema, a atenção dos pesquisadores está principalmente dirigida para escolares das classes mais desfavorecidas economicamente.

Um dado interessante encontrado por nós é que entre as 10 crianças com distúrbio auditivo, 7 pertenciam à escola carente (70\%), 2 (20\%) à escola mista, 1 (10\%) à escola de nível médio e nenhuma à escola particular.

Essa proporcionalidade diferencial encontrada entre os estratos de nossa investigação é congruente com a literatura especializada que aponta para uma maior incidência de patologias de ouvido nas famílias dos estratos sociais desfavorecidos economicamente $\left(\mathrm{ROBSON}^{5}, \mathrm{CAMBON}^{3}\right)$.

\section{Sobre a percepção dos pais quanto aos problemas visuais dos filhos}

Das 28 famílias entrevistadas (em que os filhos apresentavam distúrbio visual), verificamos que 9 sabiam do problema e 19 não haviam percebido nada.

Das 9 famílias que sabiam do problema, 2 foram informadas pela escola e as outras 7 perceberam o distúrbio pelos sinais e sintomas apresentados pela criança. É importante esclarecer que nestas famílias já havia alguém que usava óculos, o que explica que elas estivessem mais atentas para o problema.

Com relação ao grau de instrução e à renda, verificamos que este grupo de famílias pertence a estratos sociais de baixo poder aquisitivo, com renda entre 2 e 5 salários mínimos e o grau de instrução corresponde ao $1^{\circ}$ grau incompleto $(71,4 \%)$.

Quanto às 19 famílias que não perceberam o distúrbio visual de seus filhos, constituem um grupo bastante heterogêneo com relação à renda familiar (que varia de 2 até mais de 10 salários mínimos). Constatamos ainda que, em 5 dessas famílias, pelo menos um dos pais tinha $3^{\circ}$ grau completo e em 6 o grau de instrução deles era $2^{\circ}$ grau completo. É importante 
ressaltar, mais uma vez, que o referido grupo conjuga famílias com maior grau de instrução e melhores salários se comparado ao grupo anterior e, não obstante, não identificaram o problema visual de seus filhos.

Fica evidente, pois, pelos dados encontrados que, no aspecto enfocado, a probabilidade de detecção, pelos pais, de algum, distúrbio visual dos filhos, depende, sobretudo de experiências anteriores. Esse resultado inesperado contraria uma de nossas hipóteses iniciais, abrindo a possibilidade de novos pontos de partida para investigações posteriores de maior amplitude.

\section{Sobre a percepção dos pais quanto aos problemas auditivos dos filhos}

Nenhum dos pais das 10 crianças que apresentaram distúrbios de audição os percebeu. Quando comentamos com eles o problema de audição dos filhos, alguns fizeram comentários do tipo: "eu preciso gritar com ele"; "é muito desligado"; "cai muito".

Ao verificarmos o grau de instrução dessas 10 famílias, encontramos $2(20 \%)$ com o $2^{\circ}$ grau completo, 2 (20\%) com o $1^{\circ}$ grau completo e outras $6(60 \%)$ com $1^{\circ}$ grau incompleto e, no que se refere à renda familiar, apenas uma família recebia entre 6 e 10 salários mínimos.

Malgrado o tamanho reduzido deste sub-grupo de nossa amostra, os dados encontrados sugerem a necessidade de reformulação, também aqui, de nossa hipótese inicial, correspondente à percepção dos pais, e apontam para o fato da maior dificuldade de detecção de distúrbios auditivos (comparativamente aos visuais).

Uma das questões formuladas aos pais referia-se à possibilidade de compra de aparelho de correção (óculos ou aparelho para surdez) caso o filho viesse a necessitar: 18 famílias $(64,3 \%)$ das 28 em que os filhos apresentaram distúrbio de visão não podiam adquirir óculos e $100 \%$ das famílias em que os filhos apresentaram problema auditivo, não podiam adquirir aparelho para ampliação sonora.

Portanto, das 38 crianças portadoras de distúrbio visual ou auditivo, 28 (73,6\%) estariam privadas do recurso de um óculos ou aparelho de amplificação sonora para a solução de seu problema.

\section{Professores}

Uma outra hipótese desta pesquisa dizia respeito ao professor. Suponhamos que o contato direto com o estudante, durante o processo de alfabetização, facilitaria a ele detectar um distúrbio visual ou auditivo que seu aluno viesse a apresentar. 
Com relação aos distúrbios visuais, dos 15 professores entrevistados, 13 (86,6\%) não perceberam a dificuldade do aluno. Com relação aos distúrbios auditivos, apenas 2 citaram sinais e sintomas como "criança aérea", "Não se fixa nas coisas" sem, contudo, relacioná-los a um problema de audição.

Os resultados encontrados sugeririam, inicialmente, a refutação dessa hipótese (se o tratamento estatístico utilizado fosse outro). Entretanto, também neste caso, seria necessária a sua reformulação (ou substituição) uma vez que as circunstâncias de trabalho do professor hoje, sobretudo na rede oficial de ensino, dificultam um acompanhamento mais próximo dos alunos, a construção do vínculo professor-aluno e, conseqüentemente, anulam uma possibilidade maior de perceber neles problemas de visão ou audição. Entre as circunstâncias referidas estão as constantes do aluno de uma classe para outra, objetivando homogeneizá-las, a superlotação das salas de aula, as faltas freqüentes dos professores, levando a freqüentes substituições.

\section{Diretores}

Sob a hipótese de que a escola não tinha condições de resolver satisfatoriamente os distúrbios visuais e auditivos que viessem a ser detectados nos alunos, a fim de estudar este aspecto de nossa problemática, entrevistamos os diretores.

Uma das questões formuladas referia-se a se a escola rotineiramente realizava triagem visual e auditiva dos alunos.

Pelas respostas obtidas, constatamos que tanto as escolas particulares, como as da rede oficial não realizam nenhum teste e triagem de rotina.

A esse respeito, constatamos que todos os alunos de $1^{\text {a }}$ série, independente do tipo de escola freqüentada, estavam na mesma situação.

A $2^{\mathrm{a}}$ questão formulada aos diretores aos diretores indagava para aonde eram encaminhados os casos eventualmente detectados.

Pelas respostas obtidas, ficamos sabendo que, das 9 escolas da amostra, 4 encaminham para a família, 2 para instituições da comunidade e 3 para a Unidade Básica de Saúde (UBS). Com relação a este último encaminhamento, a sua inadequação é evidente, pois as UBS não contam com oftalmologistas e médicos otorrino em seu quadro profissional, precisando, portanto, reencaminhar o aluno para serviços de referência secundária ou terciária, como é o caso do Hospital das Clínicas.

Em suma, uma vez detectados problemas visuais ou auditivos nos alunos, a escola não pode resolvê-los, encontra dificuldades em seu encaminhamento e, à exceção das 
famílias de maior poder aquisitivo, existe, no final desse processo, usualmente longo e sinuoso, um último obstáculo: o da impossibilidade de aquisição do aparelho corredor.

\section{Conclusão}

A visão e a audição são dois requisitos básicos para o processo de alfabetização. No entanto, os resultados desta pesquisa mostram que a detecção dos distúrbios visuais e auditivos em escolares que ingressam no $1^{\circ} \mathrm{grau}$, enfrenta vários obstáculos e as soluções adequadas têm sido relegadas ao segundo plano ou, então, tratadas sem a seriedade que merecem a nível de educação e saúde. Sendo assim, fica evidente a necessidade de uma política eficaz, nessa área, voltada para o equacionamento da identificação precoce dos alunos que apresentam os citados distúrbios e para solução exigida, sabendo-se que esses problemas interferem não só durante o período de escolarização mas em toda a vida do indivíduo.

Sabemos também que as soluções para os problemas aqui discutidos, entre outras, não se reduzem aos aspectos técnicos, sobretudo em se tratando de uma sociedade como a brasileira, marcada por fortes contrastes sociais e por políticas governamentais que se fundamentam na marginalização de expressivos segmentos populacionais quanto aos seus direitos básicos de cidadania.

Do ponto de vista metodológico, a pesquisa - que se situa no limite entre a perspectiva positivista e sua crítica - encontrou alguns resultados inesperados (nos casos das hipóteses 1 e 2) o que coloca novos pontos de partida para futuras investigações, contribuindo, portanto, para repensar-se o conhecimento da problemática aqui analisada e de problemáticas afins.

The evaluation of visual and auditive functions of students entering the first degree of elementary school is considered a basic action of the student health.

The child upon entering the elementary school begins or continues learning the alphabet which is considered one of the most important processes of the educational area.

The child needs normal vision and hearing (or with adequate correction) to carry on this process in the easiest way.

In this paper, we tried to study the visual and auditive problems in elementary school students in the city of Ribeirão Preto, from different social layers concerning early of cases and resolution of problems (or not) found by the family and school.

UNITERMS: Student, precocious detection, vision, hearing, social stratification, family, teacher. 
La avaluación de las funciones visuales y auditivas de los alumnos ingresantes en el 1er. grado del primario, es considerada una acción fundamental de la salud del estudiante.

El niño, al ingresar en el 1er. grado inicia (o continua) el proceso de alfabetización considerado uno de los más importantes del área educacional y necesita por consiguiente visión y audición normales (o con corrección adecuada) para que ese proceso sea facilitado sea facilitado.

En este trabajo, procuramos estudiar los disturbios visuales y auditivos de los estudiantes de Ribeirão Preto, de diferentes capas sociales, en los aspectos de detección precoz, encaminamiento de los casos y solución o no por la familia y escuela de los problemas encontrados.

UNITERMOS: Estudiante, detección precoz, visión, audición, estratificación social, familia, profesor.

\section{REFERÊNCIAS BIBLIOGRÁFICAS}

01. ANDRADE, O. M. M. de. Avaliação da Saúde de Escolares de Pradópolis-SP. Ribeirão Preto. 80 p. Tese (Doutorado). Faculdade de Medicina de Ribeirão Preto, Universidade de São Paulo, 1984.

02. BEVILACQUA, M. C. Audiologia Educacional: considerações sobre audição em crianças da $1^{\text {a }}$ série do $1^{\circ}$ grau de escolas públicas. São Paulo. Dissertação (Mestrado). Pontifícia Universidade Católica, 1978.

03. CAMBON, K. et al. Middle - Ear disease in Indians of Mount Currie Reservation, British Columbia. Can. Med. Assoc. J., Ottawa, v. 93, p. 1301-5, 1965.

04. HESHIKI, Z. Triagem audiométrica em escolares de Botucatu. Rev. Ciênc. Bioméd., São Paulo, v. 3, p. 27-31, 1982.

05. ROBISON, G. C. et al. A survey of hearing loss Vancouver school children: Part I Methodology and Prevalence. Can. Med. Assoc. J., Ottawa, v. 97, p. 1199-207, 1967.

06. SELIGMAN, J. Sistemática da pesquisa audiológica em escolares de Porto Alegre. Atualização em otologia e foniatria. Porto Alegre, v. 3, n. 1, p. 15-8, 1975.

07. SILVA, G. B. Critérios de estratificação social. Rev. Saúde Públ., São Paulo, v. 15, p. 38-45, 1981. 
08. SPRENGER, A. et al. Dificuldades de linguagem e audição encontradas nos alunos que freqüentam as primeiras séries escolares. São Paulo: Secretaria de Estado da Educação/Coordenadoria de Estudos e Normas Pedagógicas, 1985.

09. STAVENHAGEN, R. Estratificação social e estrutura de classe. In: Velho, O. G. et al. Estrutura de classes e estratificação social. 3 ed. Rio de Janeiro: ZAHAR, 1971.

10. THIOLLENT, M. J. M. Crítica metodológica, investigação social e enquete operária. 3 ed. São Paulo: Poli, 1982.

11. ZANO, C. G. de S. Estudo de função visual de crianças matriculadas em uma escola pública estadual de $\mathbf{1}^{\circ}$ grau na cidade de Porto Alegre (RS). São Paulo. Dissertação (Mestrado). Escola Paulista de Medicina, 1991. 